03

\title{
Исследование влияния добавки наночастиц гидрофобного оксида кремния на коллоидную устойчивость обратных эмульсий
}

\author{
() Е.И. Михиенкова ${ }^{1}$, А.В. Минаков ${ }^{1,2}$, С.В. Лысаков ${ }^{1}$, А.Л. Неверов ${ }^{1}$, М.И. Пряжников ${ }^{1}$ \\ ${ }^{1}$ Сибирский федеральный университет, Красноярск, Россия \\ ${ }^{2}$ Институт теплофизики им. С.С. Кутателадзе СО РАН, Новосибирск, Россия \\ E-mail: EMikhienkova@sfu-kras.ru
}

Поступило в Редакцию 29 января 2021 г.

В окончательной редакции 18 марта 2021 г.

Принято к публикации 28 апреля 2021 г.

\begin{abstract}
Представлены результаты экспериментальных исследований влияния добавки наночастиц оксида кремния на стабильность обратных эмульсий на основе минеральных масел. Концентрация наночастиц в эмульсии варьировалась от 0.25 до 2 wt.\%. Исследованы соотношения объемных долей углеводородной фазы и воды 70/30, 80/20, 90/10. Рассмотрено несколько типов эмульгаторов. Показано, что даже в небольших концентрациях гидрофобные наночастицы $\mathrm{SiO}_{2}$ существенно улучшают устойчивость обратных эмульсий. Скорость дестабилизации эмульсии при добавлении 2 wt.\% наночастиц уменьшается в 1.7 раза.
\end{abstract}

Ключевые слова: эмульсия, наночастицы, стабильность, коллоидная устойчивость.

DOI: 10.21883/PJTF.2021.15.51226.18720

\begin{abstract}
Эмульсии широко используются в различных отраслях человеческой деятельности. В последние десятилетия интенсивно исследуются вопросы их применения в качестве основы для приготовления углеводородных буровых растворов, которые обладают рядом важных преимуществ по сравнению с традиционными растворами на водной основе [1]. Одним из важнейших требований, предъявляемых к любой эмульсии, является ее устойчивость к коалесценции. Для применения буровой эмульсии это требование имеет принципиальное значение. Существует большое количество разнообразных способов стабилизировать эмульсию. О способности мелкодисперсных частиц стабилизировать эмульсии известно уже более 100 лет [2]. Однако интенсивно изучать дисперсные системы, стабилизированные наночастицами, начали лишь в последние 10-20 лет [3-8]. В настоящее время активно исследуются способы стабилизации прямых (масло в воде) эмульсий в силу их перспективности для применения в фармацевтической, косметической и пищевой промышленности. В то же время данных о стабилизации наночастицами обратных эмульсий, которые в большинстве случаев используются в качестве основы для буровых растворов, практически нет.
\end{abstract}

В связи с этим в настоящей работе исследовано влияние добавки наноразмерного гидрофобного кремнезема на стабильность обратных эмульсии. Для этого была проведена серия измерений коллоидной устойчивости и электростабильности обратных эмульсий с различным содержанием водной фазы.

Для приготовления эмульсий использовалась следующая методика. Были исследованы соотношения объемных долей масло/вода 70/30, 80/20, 90/10. В эмульсию вводились гидрофобные наночастицы $\mathrm{SiO}_{2}$ со средним размером $80 \mathrm{~nm}$ и различной концентрацией: $0.25,0.5,1$,
2 wt.\%. Размер наночастиц измерялся непосредственно в масле с применением акустического и электроакустического спектрометра DT1200 (Dispersion Technologies). В качестве углеводородной основы в работе рассмотрено два вида минерального масла „REBASE“ PC-230: A2 и В2 (производство ООО „НПО „РеаСиб“). Плотность масел А2 и В2 была равна 0.79 и $0.83 \mathrm{~g} / \mathrm{cm}^{3}$, кинематическая вязкость 3 и $10 \mathrm{cSt}$ соответственно. В качестве дисперсной фазы использован водный раствор $\mathrm{CaCl}_{2} \mathrm{c}$ плотностью $1.2 \mathrm{~g} / \mathrm{cm}^{3}$. Для стабилизации эмульсий использовалось два неионогенных эмульгатора: CarboMul HT и „REBASE“ PC-510. Для разрушения конгломератов наночастиц после их добавления в углеводородную среду раствор подвергался интенсивной обработке ультразвуком. При этом для того чтобы исключить дробление дисперсной фазы до наноглобул, добавление рассола $\mathrm{CaCl}_{2}$ происходило после ультразвукового диспергирования наночастиц в углеводородной среде. Для ультразвуковой обработки использовался аппарат „Волна“ УЗТА-0.4/22-ОМ, обработка происходила в течение 5 min на максимальной мощности $400 \mathrm{~W}$. При подготовке эмульсий использовался метод крупного дробления капель, а именно механическое диспергирование в течение 30 min на трехшпиндельной мешалке Hamilton Beach и высокоскоростной мешалке на $20000 \mathrm{rpm}$ OFITE 152-18 Prince Castle. Коллоидная устойчивость эмульсий контролировалась с помощью анализатора Turbiscan LAB. Turbiscan LAB позволяет проводить анализ долговременной устойчивости образцов, а также при простых механизмах дестабилизации расчет среднего размера частиц/капель, их объемной доли и некоторых других параметров. Электростабильность эмульсий определена на анализаторе OFITE 131-50. Относительная погрешность измерений электропотенциала данным прибором равна 7\%. Для каждого образца выполнялось не менее пяти 
Электростабильность эмульсий на основе масла В2 с эмульгатором „REBASE“ PC-510 и добавкой наночастиц

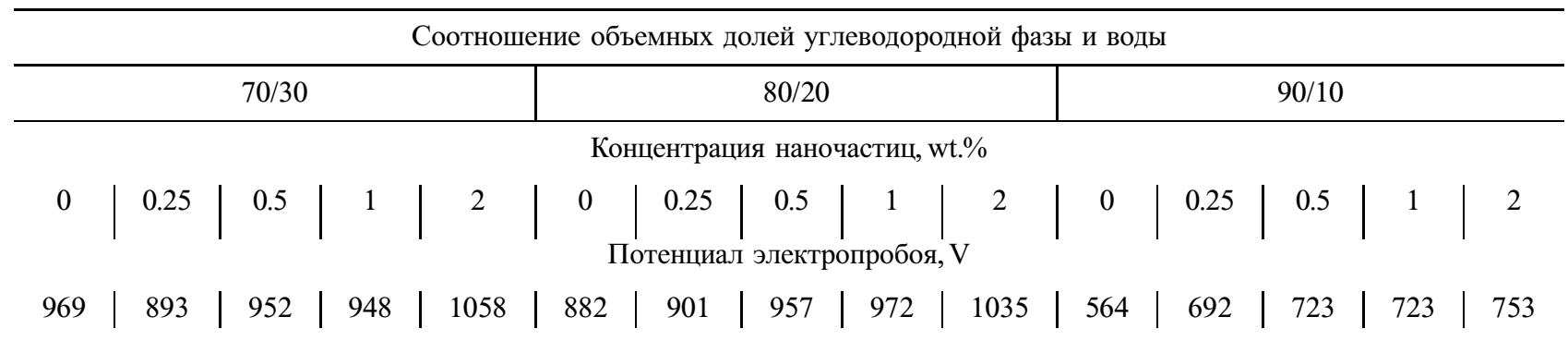

измерений. Среднеквадратичное отклонение результатов от среднего значения не превышало $2 \%$.

Вначале было проведено исследование влияния добавки наночастиц на электростабильность обратных эмульсий. Электростабильность - параметр, который косвенно характеризует агрегативную стабильность эмульсий к коалесценции глобул дисперсной фазы и коррелирует с их размером и прочностью межфазных адсорбционных слоев эмульгатора. Считается, что чем выше потенциал электропробоя, тем выше стабильность эмульсии [9]. Как видно из данных, приведенных в таблице, наибольшим значением потенциала, при котором осуществлялся электропробой, без добавки наночастиц обладала эмульсия с максимальным содержанием воды (30\%). Эта эмульсия являлась самой стабильной из рассмотренных. C уменьшением содержания дисперсной фазы коллоидная устойчивость стабильной эмульсии уменьшалась. Об этом свидетельствует уменьшение потенциала электропробоя. При добавлении наночастиц во всех случаях происходило существенное увеличение потенциала электропробоя. При этом наиболее сильное увеличение этого параметра (до 50\%) было зафиксировано для наименее устойчивой к коалесценции эмульсии с объемным содержанием углеводородной фазы и воды 90/10.

На следующим этапе было проведено исследование коллоидной устойчивости эмульсий с добавкой наночастиц на анализаторе коллоидной устойчивости Turbiscan LAB. Принцип работы Turbiscan LAB основан на методе многократного рассеяния света (multiple light scattering). С помощью данного прибора были получены профили пропускания и обратного рассеяния лазерного излучения $(880 \mathrm{~nm})$ по высоте стеклянных емкостей (виал), заполненных образцами исследуемых эмульсий. Относительная погрешность измерений обратного рассеяния в данным приборе составляет порядка $0.1 \%$.

Эволюция профилей обратного рассеяния (BS) во времени для эмульсии без добавления и с добавлением наночастиц оксида кремния приведена на рис. 1. Из профиля обратного рассеяния хорошо видны изменения в образцах с течением времени. Наиболее яркий пример демонстрирует эмульсия на основе масла В2 с соотношением масло/вода, равным 70/30. Видно, что без добавки наночастиц расслоение эмульсии происходит практически до половины длины виалы, тогда как добавка наночастиц приводит к тому, что профиль
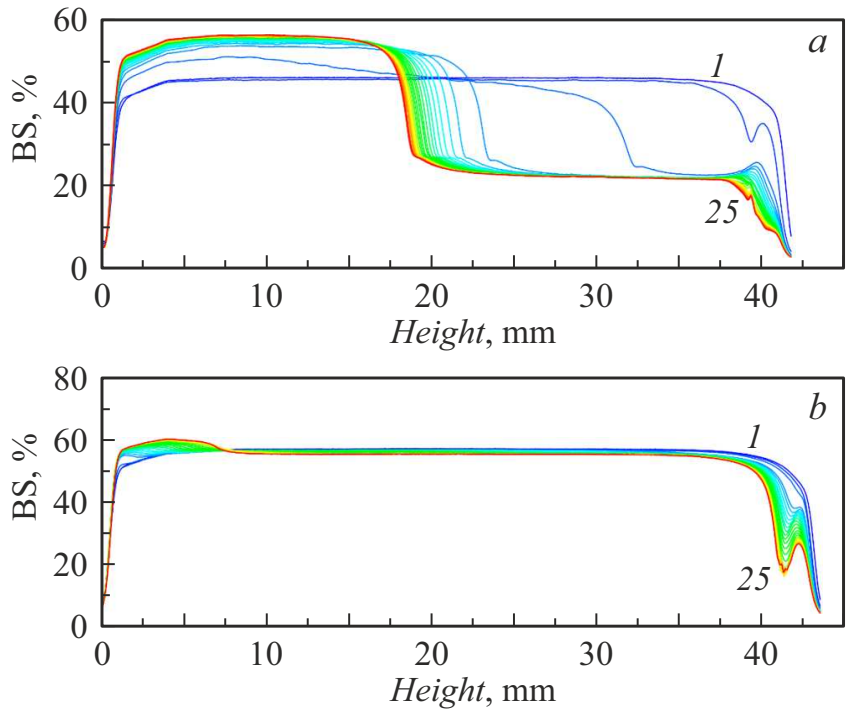

Рис. 1. Эволюция во времени обратного рассеяния излучения для эмульсии на основе масла В2 без добавки наночастиц $(a)$ и с добавкой $2 \mathrm{wt} . \%$ наночастиц $(b)$. Кривая 1 соответствует $0 \mathrm{~h}$, кривая $25-24 \mathrm{~h}$ (шаг $1 \mathrm{~h})$.

обратного рассеяния остается неизменным во времени в течение гораздо большего времени, что свидетельствует о возрастании коллоидной устойчивости эмульсии.

Для количественного сравнения устойчивости нескольких образцов Turbiscan LAB использует индекс дестабилизации (TSI). Индекс дестабилизации рассчитывается как средняя по высоте виалы разность профилей обратного рассеяния излучения в соседние моменты времени. Для расчета этих кривых используется приведенная далее формула, основанная на вычислении накопительной суммы отклонений каждого следующего скана от предыдущего. Для учета немного различающихся высот для каждого образца (поскольку невозможно заполнить виалу с точностью до $40 \mu \mathrm{m}$ по высоте) эта сумма изменений нормируется на высоту образца $H$

$$
\mathrm{TSI}=\sum_{i} \frac{\Sigma_{h}\left|\mathrm{BS}_{i}(h)-\mathrm{BS}_{i-1}(h)\right|}{H} .
$$

Чем ниже параметр TSI, тем стабильнее эмульсия. На рис. 2 представлена кинетика дестабилизации 


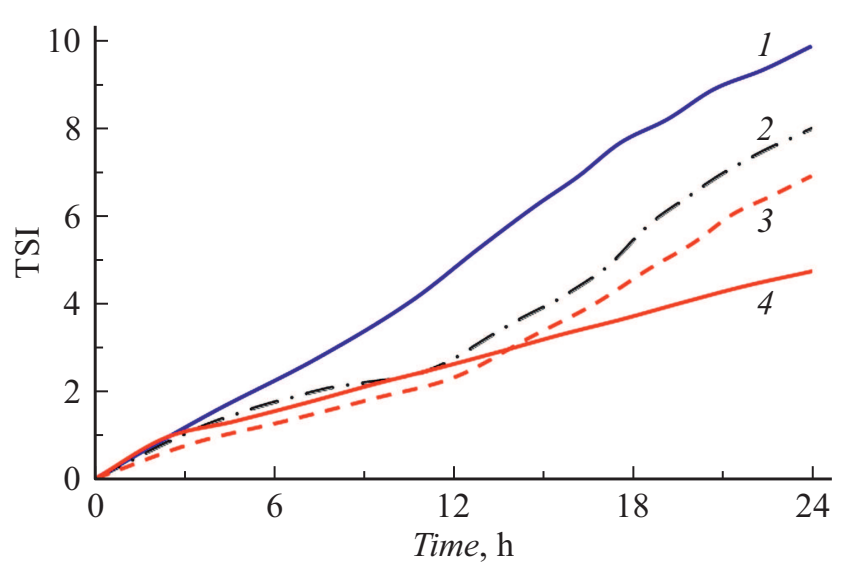

Pис. 2. Кинетика дестабилизации обратной эмульсии на основе минерального масла А2/вода с содержанием наночастиц 0 (1), 0.25 (2), 1 (3) и 2 wt.\% (4).

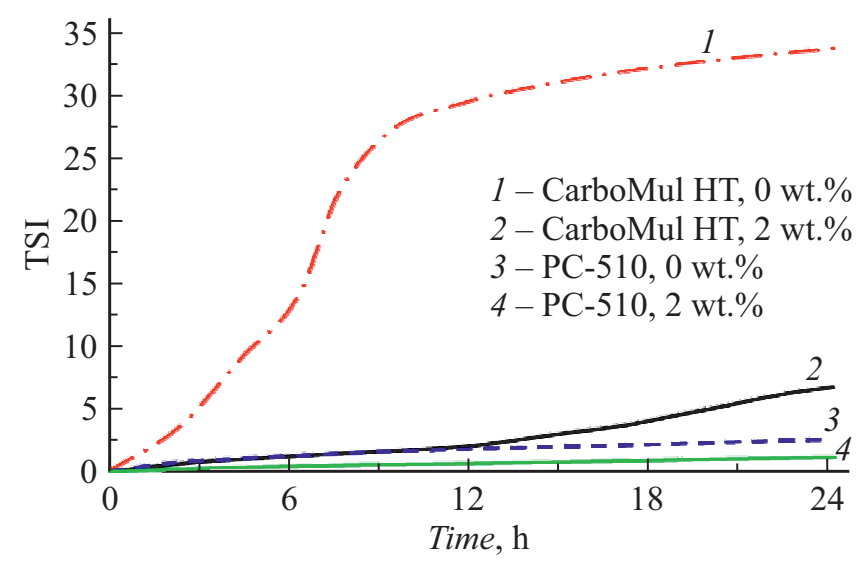

Рис. 3. Кинетика дестабилизации обратных эмульсий на основе масла В2 (70/30) с двумя различными эмульгаторами без добавления и с добавлением наночастиц.

эмульсии (70/30) на основе масла А2 с эмульгатором „REBASE“ РC-510. Наименьшую устойчивость демонстрирует образец без наночастиц. При повышении концентрации наночастиц индекс TSI начинает снижаться, наименьшее значение он имеет для концентрации $2 \mathrm{wt} . \%$. Это подтверждает положительное влияние добавок наночастиц на устойчивость дисперсной системы.

Далее было исследовано влияние вида эмульгатора и минерального масла на устойчивость стабилизированных наночастицами эмульсий. На рис. 3 показана кинетика дестабилизации обратных эмульсий на основе масла В2 (70/30) с эмульгаторами CarboMul HТ и „REBASE“ РC-510 без добавления и с добавлением наночастиц. Результаты показали, что обратные эмульсии, приготовленные при помощи эмульгатора „REBASE“ PC-510, при прочих равных условиях являлись гораздо более устойчивыми, чем в случае применения эмульгатора CarboMul HT. При использовании эмульгатора CarboMul HT происходило частичное или полное расслоение эмульсии менее чем за сутки. Эмульсии, приго- товленные при помощи эмульгатора „REBASE“ PC-510, оставались стабильными как минимум в течение недели. При добавлении 2 wt.\% наночастиц для обоих эмульгаторов наблюдалось повышение коллоидной устойчивости эмульсий. При этом наиболее значительная стабилизация происходила для изначально нестабильной эмульсии с эмульгатором CarboMul HT.

Анализ влияния свойств масел показал, что исходно обратные эмульсии на основе более вязкого масла В2 являются более стабильными по сравнению с эмульсиями на основе масла А2. При этом было установлено, что добавление $2 \mathrm{wt}$ \% наночастиц примерно в 1.7 раза уменьшает скорость дестабилизации эмульсии на основе обоих масел.

Таким образом, впервые было исследовано влияние добавок наночастиц диоксида кремния на стабильность обратных эмульсий. В результате было установлено, что даже в небольших концентрациях гидрофобные наночастицы $\mathrm{SiO}_{2}$ позволяют радикально повысить устойчивость обратных эмульсий к коалесценции. При этом положительное действие добавок наночастиц на устойчивость обратных эмульсий имеет место для различных видов минеральных масел и используемых эмульгаторов. Очевидно, что основной причиной стабилизации обратных эмульсий при введении в них наночастиц является адсорбция наночастиц на границе раздела вода-углеводородная фаза. Однако для того чтобы ответить на вопрос о том, каков конкретный механизм этого воздействия, необходимы дополнительные систематические исследования.

\section{Финансирование работы}

Исследование выполнено при финансовой поддержке Российского научного фонда в рамках проекта № 17-7920218 „Применение наножидкостей в технологиях разработки и эксплуатации нефтегазовых месторождений“, a также в рамках государственного задания ФГАОУ ВО „Сибирский федеральный университет“ FSRZ-20200012 „Лаборатория физико-математических технологий разработки трудноизвлекаемых запасов углеводородов“.

\section{Конфликт интересов}

Авторы заявляют, что у них нет конфликта интересов.

\section{Список литературы}

[1] А.В. Минаков, Е.И. Михиенкова, А.Л. Неверов, Ф.А. Бурюкин, Письма в ЖТФ, 44 (9), 3 (2018). DOI: 10.21883/PJTF.2018.09.46059.17166

[2] S.U. Pickering, J. Chem. Soc., 91, 2001 (1907). DOI: $10.1039 /$ CT9079102001

[3] А.В. Садовой, Д.Н. Браташов, А.М. Ященок, Ю.И. Свенская, Г.Б. Сухоруков, Д.А. Горин, Письма в ЖТФ, 36 (2), 87 (2010). DOI: $10.1134 / \mathrm{S} 106378501001027 \mathrm{X}$ 
[4] Д.С. Волощук, А.А. Ефименков, М.Ю. Королёва, Е.В. Юртов, Успехи в химии и хим. технологии, XXXII (10), 11 (2018).

[5] B.P. Binks, Curr. Opin. Colloid Interface Sci., 7, 21 (2002). DOI: 10.1016/S1359-0294(02)00008-0

[6] F. Leal-Calderon, V. Schmitt, Curr. Opin. Colloid Interface Sci., 13, 217 (2008). DOI: 10.1016/j.cocis.2007.09.005

[7] Y. Chevalier, M.-A. Bolzinger, Colloids Surf. A, 439, 23 (2013).

[8] E. Vignati, R. Piazza, T.P. Lockhart, Langmuir, 19, 6650 (2003). DOI: $10.1021 / \mathrm{la} 0342641$

[9] А.И. Булатов, Ю.М. Проселков, В.И. Рябченко, Технология промывки скважин (Недра, М., 1981). 